\title{
Effects of Tramp Elements on Formability of Low-carbon TRIP- aided Multiphase Cold-rolled Steel Sheets
}

\author{
Chang Gil LEE, Sung-Joon KIM, Tae-Ho LEE and Chang-Seok OH \\ Materials Processing Department, Korea Institute of Machinery and Materials, Changwon, 641-010 Korea.
}

(Received on November 15, 2003; accepted in final form on December 15, 2003)

\begin{abstract}
Four kinds of TRIP-aided cold-rolled steel sheets were fabricated with additions of tramp elements of $\mathrm{Cu}$, $\mathrm{Cr}$, and $\mathrm{Ni}$ to a basic $0.15 \mathrm{C}-1.5 \mathrm{Mn}-1.5 \mathrm{Si}-0.5 \mathrm{Cu}$ (hereafter all in wt\%) steel, and their microstructures, mechanical properties, and formability were investigated to analyze the effects of the addition of tramp elements. These steel sheets were intercritically annealed at $780-790^{\circ} \mathrm{C}$, and isothermally treated at $430^{\circ} \mathrm{C}$. Tensile tests and limiting dome height (LDH) tests were conducted, and the changes of retained austenite volume fractions as a function of tensile strain were measured using X-ray diffraction. The formability of the $\mathrm{Cu}$ - and Ni-containing cold-rolled steel sheets was greatly improved as the strain-induced transformation of retained austenite was sustained up to the high strain region due to their high volume fraction and stability of retained austenite. On the other hand, the Cr-containing steel sheets showed a dual-phase structure of ferrite and martensite resulting from low volume fraction and stability of retained austenite and a large amount of transformed martensite. These findings indicated that when tramp elements such as $\mathrm{Cu}, \mathrm{Cr}$, and $\mathrm{Ni}$ were positively used, low-carbon TRIP-aided cold-rolled steel sheets having mechanical properties suitable for various application purposes and excellent formability could be successfully achieved.
\end{abstract}

KEY WORDS: TRIP steel; tramp element; formability; retained austenite; strain-induced transformation.

\section{Introduction}

Cold-rolled steel sheets, which show excellent ductility and formability in spite of somewhat low strength, have been preferred in automotive industries because there are some technical manufacturing problems including the difficulties involved in forming sheets. ${ }^{1-4)}$ However, the worldwide attention to environmental issues is seriously calling for enhancement in fuel efficiency, reduction of emission gas, and better recycling of resources as well as improved driving performance and safety.

Recently, TRIP (transformation induced plasticity)-aided steels are recognized as new concept steels, in which both high strength and high ductility can be achieved from the strain-induced transformation of retained austenite. ${ }^{5,6}$ Particularly, C-Si-Mn TRIP-aided cold-rolled steel sheets, whose basic structure is composed of ferrite, bainite, and retained austenite, have simpler alloying elements and are more applicable to various heat treatments. They are evaluated to have excellent recyclability as well as high strength and ductility, ${ }^{1,7)}$ and thus are expected to be widely applied as structural materials for automobiles in the future.

One of the new directions currently undertaken in the development of new steels aiming at improved mechanical properties and better recyclability is the positive application of tramp elements. Tramp elements refer to those retained and stored inside steels since they are not easily eliminated even in the refining process, which is one of the important process in steel scrap recycling. They are generally known to deteriorate mechanical properties, tensile properties in particular. ${ }^{8-12)}$ However, some representative tramp elements such as $\mathrm{Cu}, \mathrm{Cr}$, and $\mathrm{Ni}$ can be favorably applied to improve mechanical properties of steels. Therefore, positive application of them can contribute to the development of excellent advanced steels and to the more efficient use of resources. One example is the addition of a small amount of $\mathrm{Cu}$ to steels, which was reported to promote the precipitation strengthening due to the precipitation of several nanometer-sized quasi-stable 9R phases of orthorhombic structure or stable $\varepsilon$ - $\mathrm{Cu}$ particles of face centered cubic structure. ${ }^{11,13)}$ Also, recent studies presented enhanced mechanical properties by $\mathrm{Cu}$ addition to TRIP-aided steels. ${ }^{11,14-16)}$ It was also confirmed that the containment of tramp elements $\mathrm{Cu}, \mathrm{Cr}$, and $\mathrm{Ni}$ in TRIP-aided cold-rolled steel sheets could work favorably for the enhancement of mechanical properties. ${ }^{15)}$ Despite the generally accepted knowledge of excellent mechanical properties of TRIPaided steels, TRIP-aided cold-rolled steel sheets in particular, studies on the formability are yet to come.

In the present study, the effects of tramp elements on the formability were investigated in TRIP-aided cold-rolled steel sheets, to which $\mathrm{Cu}, \mathrm{Cr}$, and $\mathrm{Ni}$ were added alone or in combination. This study also provided the basic data for the development of high-strength and high-formability TRIPaided cold-rolled steel sheets through active utilization of tramp elements. 


\section{Experimental}

Four kinds of $0.8-\mathrm{mm}$-thick cold-rolled steel sheets (basic composition; $0.15 \mathrm{C}-1.5 \mathrm{Mn}-1.5 \mathrm{Si}-0.5 \mathrm{Cu} \quad(\mathrm{wt} \%)$ ) with addition of $0.4 \% \mathrm{Cr}$ and $\mathrm{Ni}$, either alone or in combination, were fabricated by vacuum induction melting, hot rolling, and cold rolling. They are referred to as ECO-6, 7, 8 , and 9 steel sheets, whose chemical compositions are listed in Table 1. Based on the results from various heat-treatment conditions, those showing the most excellent mechanical properties were chosen; that is, 5-min intercritical annealing at $780-790^{\circ} \mathrm{C}$ where the volume fraction ratio of ferrite and austenite is 50:50,3-min isothermal treatment at $430^{\circ} \mathrm{C}$, and then air-cooling.

The heat-treated cold-rolled steel sheets were first etched in a $4 \%$ nital solution, etched again in a sodium metabisulfite solution $\left(\mathrm{Na}_{2} \mathrm{~S}_{2} \mathrm{O}_{3} \cdot \mathrm{H}_{2} \mathrm{O} 10 \mathrm{~g}+\mathrm{H}_{2} \mathrm{O} 100 \mathrm{~mL}\right),{ }^{14)}$ and observed by an optical microscope. Room-temperature tensile tests were conducted on plate-type specimens (longitudinal direction) with a gage length of $25 \mathrm{~mm}$ and a gage width of $6.3 \mathrm{~mm}$ at a crosshead speed of $2.5 \mathrm{~mm} / \mathrm{min}$. Engineering stress-strain curves were obtained from the tensile test, and then were converted to true stress-true strain curves to determine the strain hardening exponent, $n$, in the uniform strain range from 5 to $20 \%$. After the tensile specimens were deformed at $15 \%$, the thickness and width of the gauge section before and after the deformation were measured to obtain the plastic strain ratio, $r$.

$$
r=\varepsilon_{0} / \varepsilon_{\mathrm{f}}=\ln \left(w_{0} / w_{\mathrm{f}}\right) / \ln \left(t_{0} / t_{\mathrm{f}}\right)
$$

Here, $w$ and $t$ refer to the width and the thickness of the gauge section, respectively, while the subscripts 0 and $f$ refer to pre- and post-deformation, respectively.

Volume fraction of retained austenite was measured using an X-ray diffractometer. Specimens were prepared by polishing both mechanically and chemically sheets into half of the thickness. Mo- $\mathrm{K}_{\alpha}$ characteristic ray was used, and the volume fraction of retained austenite, $V_{\gamma}$, was calculated from the integrated intensity of ferrite and austenite peaks using the equation, $V_{\gamma}=1.4 I_{\gamma} /\left(I_{\alpha}+1.4 I_{\gamma}\right) .{ }^{17,18)}$ Here, $I_{\gamma}$ is the average integrated intensity obtained at $220_{\gamma}$ and $311_{\gamma}$ peaks, and $I_{\alpha}$ is that obtained at $211_{\alpha}$ peak. Stability of retained austenite was also evaluated by a strain-induced martensitic transformation rate formula, which was recently suggested by Chung ${ }^{19)}$ and Chang et al. ${ }^{20)}$ :

$$
\log \left[\ln f_{\mathrm{s}} /\left(f_{\mathrm{s}}-f\right)\right]=\log \kappa+m \log \varepsilon
$$

where $f_{\mathrm{s}}$ and $f$ refer to the saturated martensite volume fraction and the martensite volume fraction transformed during deformation, respectively, while $\varepsilon$ and $m$ refer to the true strain and the deformation mode coefficient, respectively. $\kappa$ is defined to be the stability coefficient of retained austenite.

In order to evaluate the formability of the cold-rolled steel sheets, limiting dome height (LDH) tests were conducted using a hemispheric punch. A schematic diagram of this LDH test is shown in Fig. 1. Minimum limiting dome height, $L D H_{\text {o }}$, was obtained from 200-mm-long rectangular specimens with varying width. The rectangular specimens were marked with circular grids by electro-chemical etching method, and were deformed until either local necking or
Table 1. Chemical compositions of cold-rolled steel sheets used. (wt $\%$ )

\begin{tabular}{cccccccc}
\hline Steel & $\mathrm{C}$ & $\mathrm{Si}$ & $\mathrm{Mn}$ & $\mathrm{Cu}$ & $\mathrm{Cr}$ & $\mathrm{Ni}$ & $\mathrm{Fe}$ \\
\hline ECO-6 & 0.14 & 1.49 & 1.51 & 0.51 & - & - & Bal. \\
ECO-7 & 0.15 & 1.52 & 1.51 & 0.51 & 0.39 & - & Bal. \\
ECO-8 & 0.15 & 1.53 & 1.52 & 0.51 & - & 0.41 & Bal. \\
ECO-9 & 0.15 & 1.55 & 1.50 & 0.50 & 0.39 & 0.41 & Bal. \\
\hline
\end{tabular}

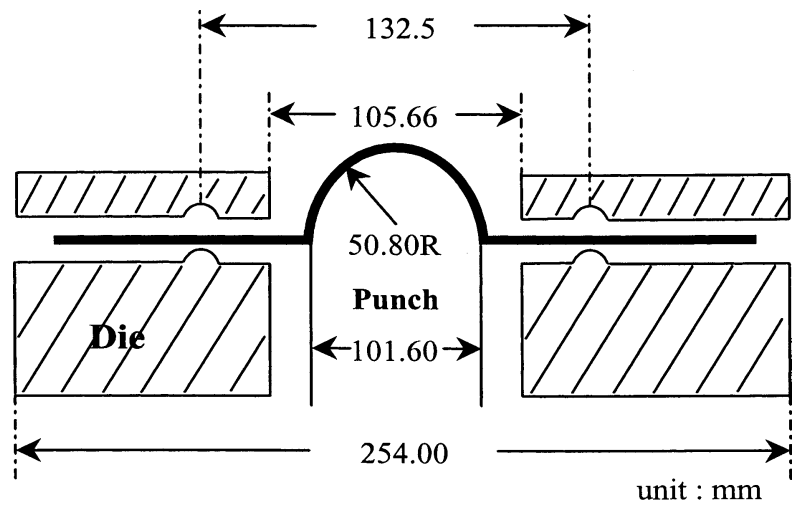

Fig. 1. Schematic diagram of the limiting dome height (LDH) test.

fracture occurred. The forming limit curve (FLC) was drawn by measuring major strain, $\varepsilon_{1}$, and minor strain, $\varepsilon_{2}$, together with the strains of the locally necked region and the un-necked region, using an optical grid analyzer after the limit strain was established.

\section{Results}

\subsection{Microstructure}

Figures 2(a) through 2(d) are optical micrographs of the four heat-treated cold-rolled steel sheets. These specimens were intercritically annealed for $5 \mathrm{~min}$ at temperatures where the volume fraction ratio of ferrite and austenite is $50: 50 ; 780^{\circ} \mathrm{C}$ for the ECO-6 and ECO-7 steels, and $790^{\circ} \mathrm{C}$ for the ECO- 8 and ECO-9 steels. When the specimens are etched by a sodium metabisulfite solution, it is easier to define the phases since ferrite is displayed as gray, bainite or martensite as black, while retained austenite as white. ${ }^{14)}$ In all the steels, most retained austenites are connected with adjacent ferrites, bainites, or martensites, while some are isolated in ferrite grains. There are some film-type retained austenites located in bainite or martensite lath boundaries, although they are not easily identified in Figs. 2(a) through 2(d). Volume fractions of retained austenite vary with steels, being about $15 \%$ in the ECO-6 steel, about $16 \%$ in the ECO- 8 steel, and below $10 \%$ in the ECO-7 and ECO-9 steels.

\subsection{Mechanical Property and Retained Austenite Vol- ume Fraction}

Table 2 summarizes tensile properties and volume fractions of retained austenite for the four steels. Yield strength of the ECO- 6 and ECO- 8 steels is about $500 \mathrm{MPa}$, and that of the ECO-9 steel is slightly lower than this. The ECO-7 steel shows the lowest yield strength of about $420 \mathrm{MPa}$. Tensile strength of the ECO-7 and ECO-9 steels is high at around $1000 \mathrm{MPa}$, and that of the ECO-6 and ECO- 8 steels 

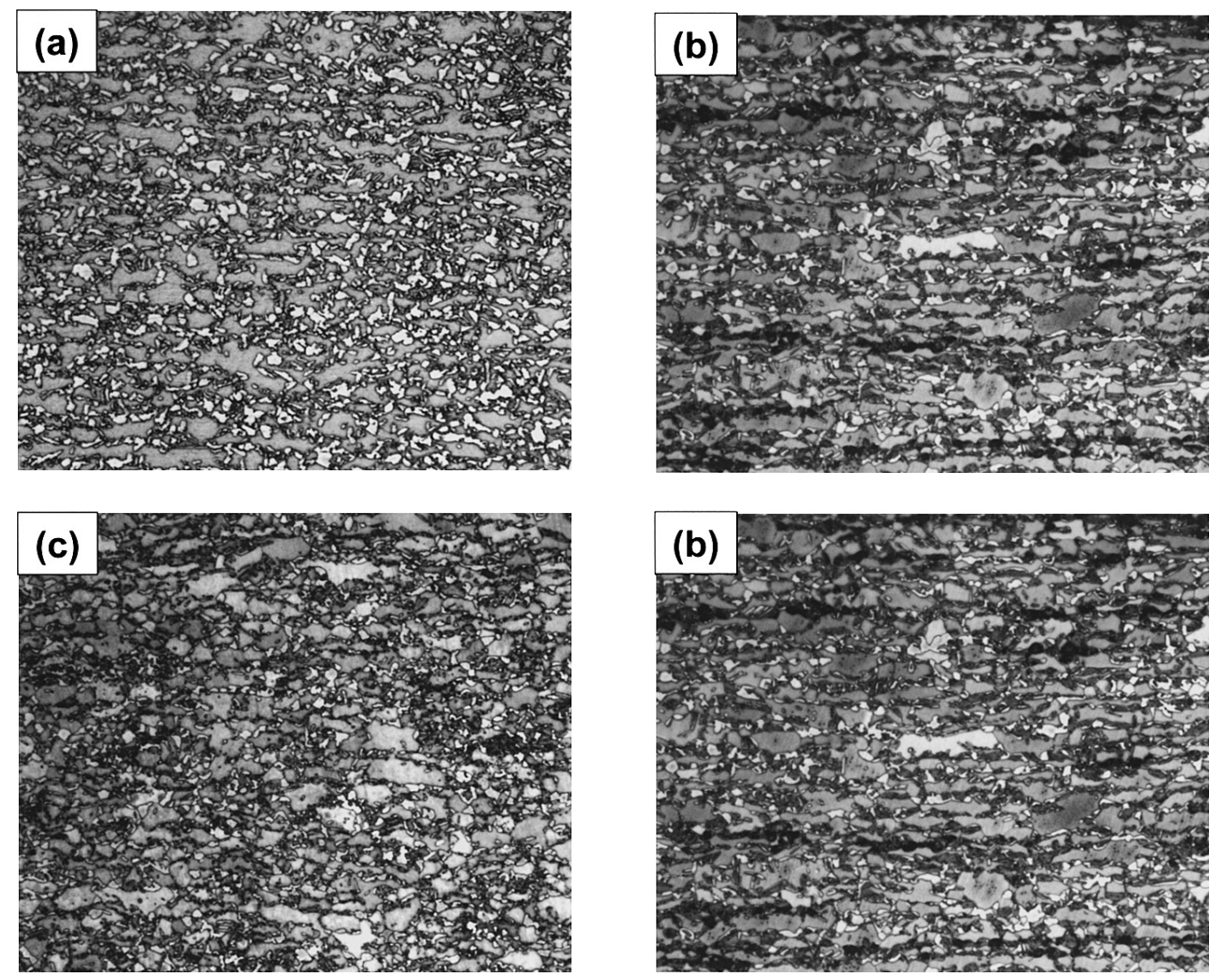

Fig. 2. Optical micrographs of the (a) ECO-6, (b) ECO-7, (c) ECO-8, and (d) ECO-9 steels. Etched by $4 \%$ nital and $10 \%$ sodium metabisulfite solutions.

Table 2. Room-temperature tensile properties and volume fraction of retained austenite of cold-rolled steel sheets.

\begin{tabular}{|c|c|c|c|c|c|c|c|c|}
\hline \multirow{2}{*}{ Steel } & \multirow{2}{*}{$\begin{array}{c}\text { Y.S. } \\
\text { (MPa) }\end{array}$} & \multirow{2}{*}{$\begin{array}{c}\text { T.S. } \\
\text { (MPa) }\end{array}$} & \multicolumn{2}{|c|}{ Elong. (\%) } & \multirow{2}{*}{$\begin{array}{l}\text { TS } \times \text { Elong. } \\
\text { GPa } \% \text { (Total) }\end{array}$} & \multirow{2}{*}{$n$} & & \multirow{2}{*}{$\begin{array}{l}V_{10} \\
(\%)\end{array}$} \\
\hline & & & Uniform & Total & & & & \\
\hline $\mathrm{ECO}-6$ & 505 & 817 & 28.4 & 36.4 & 29.7 & 0.28 & 0.93 & 14.7 \\
\hline ECO-7 & 425 & 990 & 14.9 & 20.4 & 20.1 & 0.19 & 0.77 & 8.9 \\
\hline ECO-8 & 492 & 838 & 25.4 & 32.0 & 26.8 & 0.26 & 0.88 & 16.2 \\
\hline ECO-9 & 486 & 1066 & 13.7 & 18.1 & 19.3 & 0.16 & 0.87 & 8.5 \\
\hline
\end{tabular}

is low at about $820 \mathrm{MPa}$. In the case of total elongation, the ECO-6 and ECO-8 steels show high elongation above 30\%, but the ECO-7 and ECO-9 steels show low elongation less than $20 \%$. This trend also holds in the case of uniform elongation. Strain hardening exponts, $n$, of the ECO- 6 and ECO-8 steels are relatively high at 0.28 and 0.26 , respectively, whereas the ECO-7 and ECO-9 steels have low $n$ values less than 0.20 . Plastic strain ratio, $r$, is the highest in the ECO-6 steel at 0.93, and the lowest in the ECO-7 steel at 0.77 . Those of the ECO- 8 and ECO-9 steels are 0.88 and 0.87 , respectively.

The changes in work hardening rate, $d \sigma / d \varepsilon$, as a function of true strain are shown in Fig. 3. The $d \sigma / d \varepsilon$ of the ECO-6 and ECO- 8 steels gradually decreases up to the true strain of 0.25 , and the ECO- 6 steel shows the highest level of $d \sigma / d \varepsilon$ in the region of true strain 0.10 and above. The $d \sigma / d \varepsilon$ of the ECO-7 and ECO-9 steels is abruptly reduced with increasing true strain, and deformation is terminated at the low strain of about 0.15 . These data indicate that the

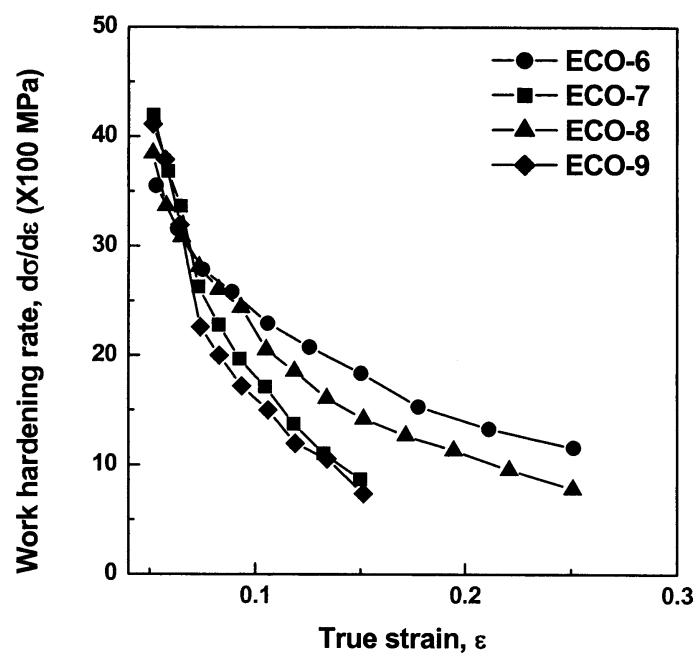

Fig. 3. Work hardening rate, $d \sigma / d \varepsilon$, as a function of true strain.

ECO-6 and ECO-8 steels would show better formability because of their more excellent uniaxial elongation than the other two steels.

Mechanical properties, particularly tensile elongation and values of $n$ and $r$, are closely related with retained austenite volume fraction. To produce TRIP effect, it is generally known that the volume fraction of retained austenite should be more than $10 \%{ }^{21,22)}$ In consideration of this, the ECO- 6 and ECO- 8 steels, having retained austenite volume fraction of more than $15 \%$, are expected to show sufficient TRIP effect. In other words, higher retained 


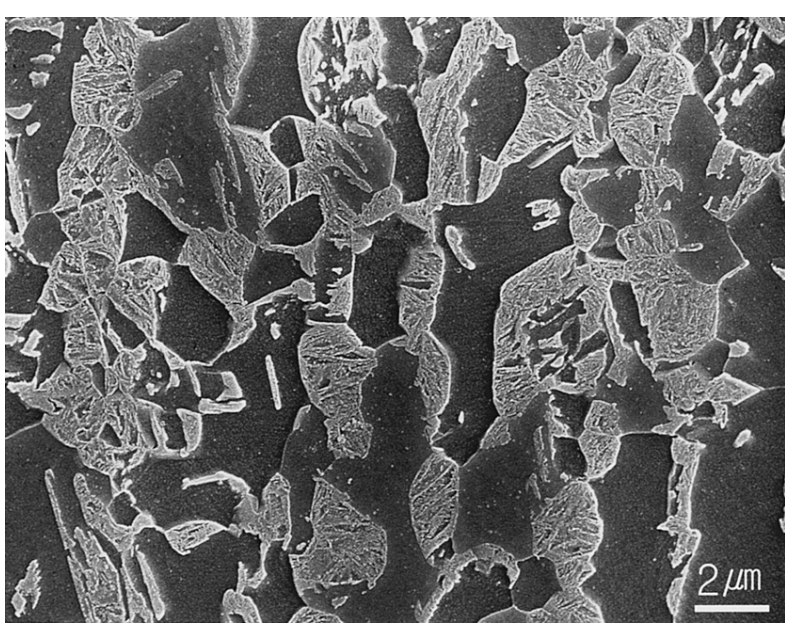

Fig. 4. SEM micrograph of the ECO-9 steel, showing the formation of martensite having lath structure.

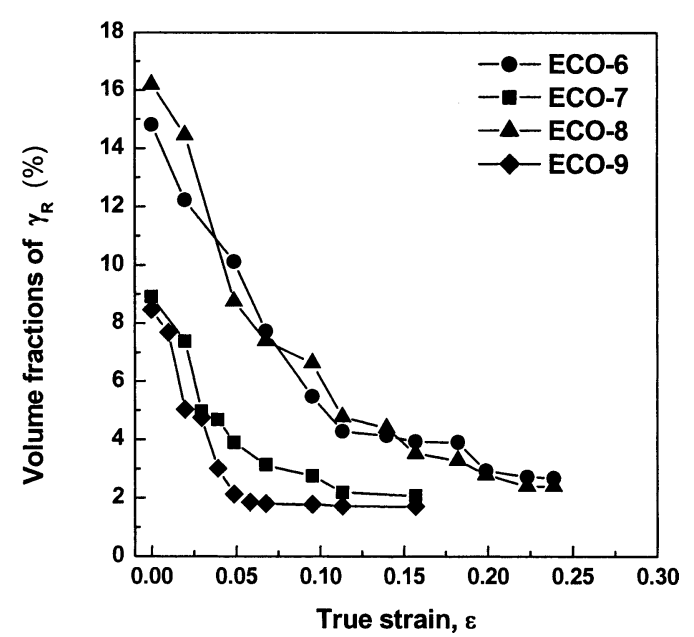

Fig. 5. Volume fraction changes of retained austenite as a function of true strain

austenite volume fraction can lead to increased tensile elongation due to the strain-induced transformation, which also brings the higher values of $n$ and $r$. On the other hand, the ECO-7 and ECO-9 steels have very low retained austenite volume fractions. Figure 4 is an SEM micrograph of the ECO-9 steel. In this figure, it can be seen lots of martensite with lath structure. The same was confirmed in the ECO-7 steel. This indicates that in the cases of the ECO-7 and ECO-9 steels, in which a large amount of martensite is formed during cooling before or after the isothermal treatment, the volume fraction of retained austenite is reduced, and the TRIP effect is overridden by the dual phase strengthening effect; thus, showing high strength but low ductility.

\subsection{Stability of Retained Austenite}

Figure 5 presents the changes in volume fraction of retained austenite as a function of true strain. In the ECO-9 steels, the volume fraction of retained austenite dramatically drops in the initial strain region below 0.05 , and it hardly changes in the strain region of 0.07 and above. In the ECO6 and ECO- 8 steels, it is abruptly reduced up to the true strain of 0.12 , after which it shows a mild reduction, indicating that the martensitic transformation is in progression up to the strain of 0.25 .

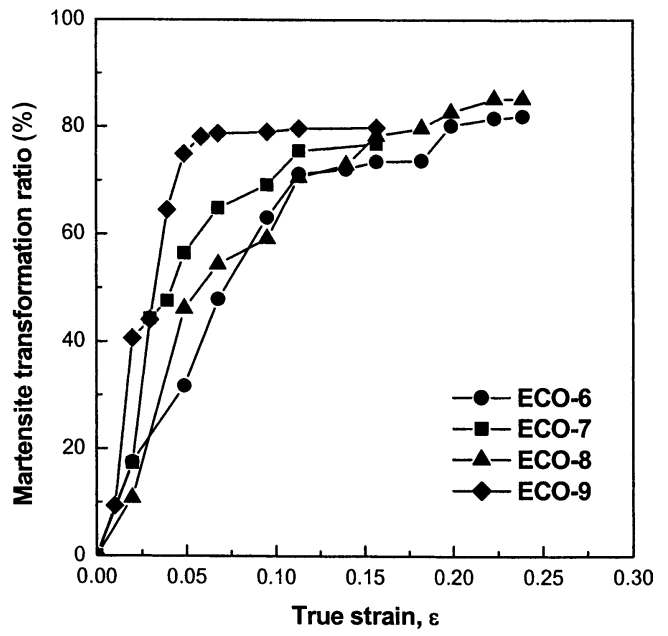

Fig. 6. Martensite transformation ratio changes as a function of true strain.

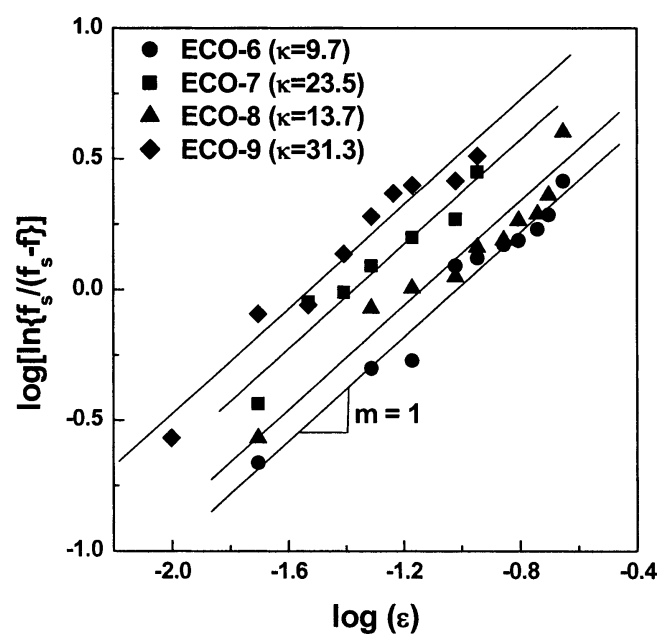

Fig. 7. Relationship between $\log \left[\ln f_{\mathrm{s}} /\left(f_{\mathrm{s}}-f\right)\right]$ and $\log \varepsilon$. The deformation mode coefficient as represented by the slope, $m$, is 1.0 .

Figure 6 shows the martensite transformation ratio converted from the changes in retained austenite volume fraction of Fig. 5 as a function of true strain. In the ECO-6 and ECO-8 steels, the martensitic transformation persists up to the high strain region of 0.25 , and the martensite transformation ratio of the ECO- 8 steel in the low strain region below 0.1 is higher than that of the ECO-6 steel, after which both show similar values. Although the martensite transformation ratio of the ECO-7 steel shows the same pattern as that of the ECO- 8 steel, the ECO-7 steel shows the higher martensite transformation ratio overall in the strain region of 0.16 or below. Unlike other steels, in the ECO-9 steel, the martensitic transformation reaches the saturation at the strain of about 0.05 . In the ECO-7 and ECO-9 steels, however, the martensitic transformation is terminated at the strain of about 0.18 .

The relationship between $\log \varepsilon$ and $\log \left[\ln f_{\mathrm{s}} /\left(f_{\mathrm{s}}-f\right)\right]$ was interpreted by applying Eq. (2) to the results of Fig. 5, and is graphed in Fig. 7. The saturated volume fraction of martensite was measured to be $12.1 \%$ in the ECO- 6 steel, $6.8 \%$ in the ECO-7 steel, $13.8 \%$ in the ECO- 8 steel, and $6.8 \%$ in the ECO-9 steel, respectively. The slope of straight lines, $m$, in Fig. 7 and Eq. (2), being the deformation mode 
coefficient, equals 1.0 in $\mathrm{C}-\mathrm{Si}-\mathrm{Mn}$ TRIP-aided steels, and is known to have specific values depending on alloying compositions. ${ }^{19)}$ The stability coefficient of retained austenite, $\kappa$, is low in the ECO- 6 steel, and increases in the order of the ECO-8, ECO-7, and ECO-9 steels. It is thus found that the ECO-6 steel has the most stable retained austenite, whereas the ECO-9 steel has the least stable retained austenite.

\subsection{Formability}

Figure 8 shows the results of the minimum limiting dome height, $L D H_{0}$, measured under plane strain and dry lubrication conditions. Generally, in the results from the limiting dome height (LDH) test, $L D H_{\mathrm{o}}$ depends on the specimen width, and typically exists when the specimen width ranges from 126 to $132 \mathrm{~mm}$ in cold-rolled steel sheets for automobiles. ${ }^{23)}$ Here, $L D H_{\mathrm{o}}$ is a barometer of the formability of steel sheets used in the stamping process, and thus the higher $L D H_{\mathrm{o}}$ indicates the better formability. ${ }^{23)}$ According to Fig. 8, the $L D H_{\text {o }}$ of the ECO-6 steel is 27.2 $\mathrm{mm}$ at the specimen width of $129 \mathrm{~mm}$, implicating that it has the best formability. On the contrary, in the ECO-7 and ECO-9 steels, $L D H_{\mathrm{o}}$ values are around $20 \mathrm{~mm}$, and particularly the ECO-9 steel has the worst formability.

Figure 9 shows forming limit curves (FLCs) obtained from the measurements of the deformed circular grids by

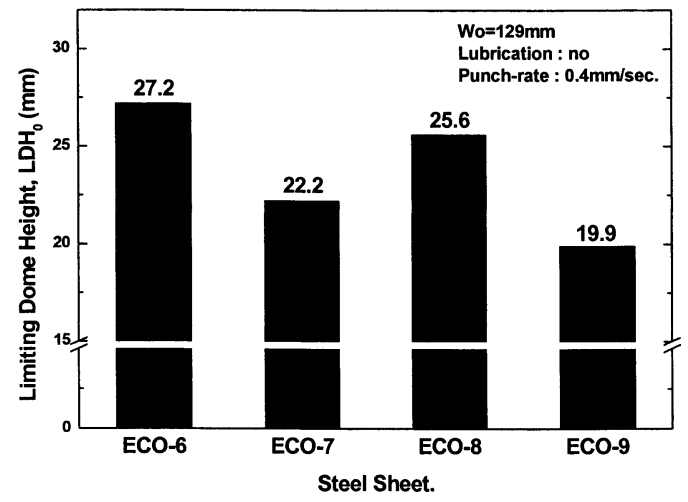

Fig. 8. Bar graphs showing minimum limiting dome height, $L D H_{o}$, measured under plane strain and dry lubrication conditions.

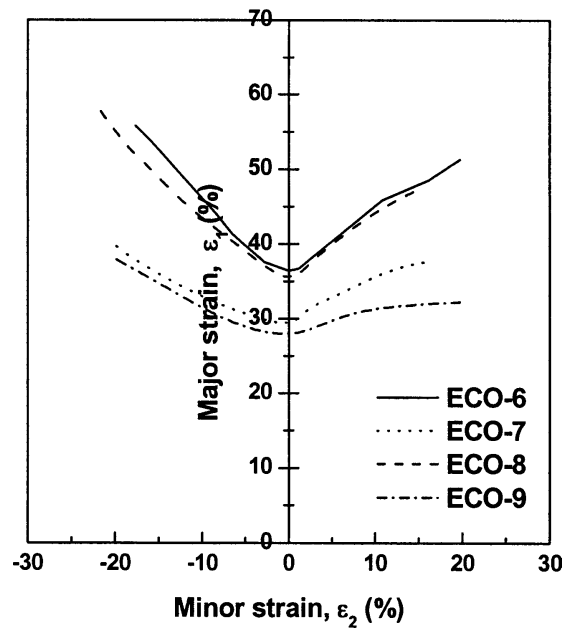

Fig. 9. Forming limit curves obtained from the measurements of the deformed circular grids by an optical grid analyzer. an optical grid analyzer. In general, the higher FLC is evaluated as the better formability, and the value of the limit plane strain, $F L C_{0}$, corresponding to the lowest point in a plane strain mode of $-0.1<\varepsilon_{2}<0.2$ typically indicates a typical barometer used to evaluate the formability. ${ }^{24,25)}$ The ECO-6 steel having the highest $F L C_{0}$ and the ECO-8 steel showing similar value as the ECO- 6 steel are considered to have excellent formability. The ECO-7 and ECO-9 steels whose $F L C_{\mathrm{o}}$ values are much lower than those of the ECO6 and ECO- 8 steels have poor formability.

\section{Discussion}

\subsection{Correlation of Strain-induced Transformation and Formability}

According to earlier studies concerned with TRIP-aided cold-rolled steel sheets, the stability as well as the volume fraction of retained austenite have been recognized as important factors directly affecting the strain-induced transformation behavior and ductility enhancement. According to Matsumura's study ${ }^{7)}$ on this, the ductility enhancement of steel sheets containing retained austenite results from the delayed occurrence of necking up to high strain region as the strain hardening of ferrite grains is recovered when the stress concentration is relaxed by the strain-induced transformation of retained austenite during plastic deformation. When ferrite, bainite, and retained austenite coexist, closer examination of the strain-induced transformation of retained austenite indicates that ferrite is strain-hardened and that strain energy is accumulated in ferrite grains due to dislocation pile-up. The accumulated strain energy here provides the driving force required for the strain-induced transformation of retained austenite to martensite. ${ }^{26)}$ Upon the occurrence of strain-induced transformation, this energy is absorbed, and is accompanied by the relaxation of dislocation pile-up and the softening of ferrite grains. Afterwards, the softened ferrite grains are strain-hardened again by martensite, and this process repeats while the strain-induced transformation of retained austenite continues on. Since resistance to deformation is large when retained austenite is stable, the strain-induced transformation of retained austenite can proceed quite steadily even under high strains, thereby preventing abrupt deterioration of strain hardenability and delaying the occurrence of necking up to the high strain region.

For this reason, the ECO-6 and ECO- 8 steels having higher stability of retained austenite show high strain hardening exponent and high tensile and uniform elongation, together with high strength above $800 \mathrm{MPa}$. On the other hand, the ECO-7 and ECO-9 steels have ultra-high strength above $1000 \mathrm{MPa}$, low tensile elongation of about $20 \%$, and high strain hardenability in the beginning of deformation as described in Table 2 and Fig. 3, and thus have similar properties to those of dual phase steels. This is because in the ECO-7 and ECO-9 steels, the strain-induced transformation proceeds rapidly in the initial stage of deformation as they have a large amount of martensite (Fig. 4) and also show the low volume fraction and stability of retained austenite. This strain-induced martensite transformation behavior directly affects the formability.

In general, in sheet metal forming, the formability is 
mainly evaluated by plastic strain ratio, $r$, and strain hardening expoent, $n$. Keeler and Backofen ${ }^{27)}$ reported that the higher $n$ in press forming indicated the more homogeneous strain and the higher stretching performance. Whiteley, ${ }^{28)}$ based on the results from deep drawing tests of round blanks, confirmed that the increase in the averaged value of $r$ was accompanied with the increased limit drawing ratio. Actual investigation into the formability of each steel sheet reveals that the ECO-6 and ECO-8 steels have not only higher strain hardening index and plastic strain ratio than the other two steel sheets (Table 2) but also higher values of $L D H_{\mathrm{o}}$ and $F L C_{\mathrm{o}}$, thereby confirming the better formability of them. As discussed earlier, this is because the strain-induced martensite transformation and strain hardening continue up to the high strain region beyond 0.25 due to the high stability of retained austenite.

\subsection{Effects of Added Elements}

This study confirms that the added tramp elements directly affect the volume fraction and stability of retained austenite and the strain-induced transformation, and thus determine the mechanical properties and formability of steel sheets. The $\mathrm{Cu}$-added ECO-6 steel, having relatively high retained austenite volume fraction of about $15 \%$ and the lowest stability coefficient, shows the best tensile properties and formability. $\mathrm{Cu}$, as an austenite stabilizer, works favorably for the formation of retained austenite and accordingly for the increase in its volume fraction accompanied with the enhancement of mechanical properties. Authors previously reported on the considerable enhancements achieved with a $0.15 \mathrm{C}-1.5 \mathrm{Si}-1.5 \mathrm{Mn}$ low-carbon TRIP-aided cold-rolled steel sheet by adding $0.5 \% \mathrm{Cu}$ to it, which had highly increased retained austenite volume fraction, equal level of stability, and improved tensile elongation, formability, and strengths. ${ }^{29)}$ Besides, it is known that ferrite grain strengthening can be achieved by a small amount of $\mathrm{Cu}$ addition because fine 9R or $\varepsilon$-Cu particles are precipitated in ferrite grains. ${ }^{11,13)}$ This can be a way to reduce the hardness gap between the soft ferrite and the hard bainite or martensite, which has long posed a problem in forming TRIP-aided cold-rolled steel sheets. In the case of $1.0 \% \mathrm{Cu}$ addition, it was generally reported that the effect of precipitation strengthening was visible only when aged for several tens of minutes in the temperature range from 400 to $700^{\circ} \mathrm{C}^{30,31)}$ However, because the cold-rolled steel sheets used in this study including the ECO- 6 steel contained $0.5 \% \mathrm{Cu}$ were isothermally treated at a low temperature of $430^{\circ} \mathrm{C}$ and for a shorter period of time of $3 \mathrm{~min}$, it is hard to expect the precipitation strengthening of $9 \mathrm{R}$ or $\varepsilon$-Cu particles. Excellent tensile properties and formability of the ECO-6 steel must be derived from the combined effects of the solid solution strengthening arising from $\mathrm{Cu}$ solution in ferrite and the higher TRIP effect due to the increase in the retained austenite volume fraction. These results of the ECO-6 steel confirm the significance of the addition of $\mathrm{Cu}$, a tramp element, in alloy designing in order to develop TRIP-aided steels with excellent mechanical properties.

The $\mathrm{Cu}$-and-Ni-added ECO-8 steel shows slightly lower retained austenite stability, tensile elongation, and formability than the Cu-added ECO-6 steel, but has higher retained austenite volume fraction and tensile strength. It shows superior uniaxial tensile properties and formability in comparison with the ECO-7 and ECO-9 steels. This is because $\mathrm{Ni}$, a representative austenite stabilizer, is solved in austenite during intercritical annealing, stabilizes austenite, and consequently forms higher volume fraction of retained austenite during subsequent isothermal treatment. Although $\mathrm{Cu}$ addition leads to strengthening of ferrite grains, it has a shortcoming of possible occurrence of hot shortness during continuous casting or hot-rolling processes. ${ }^{8,9,32)}$ This hot shortness arises when the liquid phase of $\mathrm{Cu}$ concentrated at high temperatures infiltrates into austenite grain boundaries. ${ }^{11)}$ In order to prevent this, $\mathrm{Ni}$ is added typically in the amount corresponding to 0.7 time of $\mathrm{Cu}$ addition. ${ }^{33)}$ Since $\mathrm{Ni}$ can have the preventative effect of hot shortness in addition to increased retained austenite volume fraction, it can be usefully applied in combination with $\mathrm{Cu}$ to the development of low-carbon TRIP-aided cold-rolled steel sheets with excellent properties.

In the case of the Cr-containing ECO-7 and ECO-9 steels, strength visibly increases, whereas retained austenite volume fraction and elongation are dramatically reduced. They show the tensile behaviors similar to those of dual phase steels, much different from those of the ECO-6 and ECO-8 steels. As observed in Fig. 4, the microstructure is composed of dual phases of ferrite and martensite. According to the $\mathrm{Fe}-\mathrm{Cr}$ binary phase diagram, ${ }^{34)}$ a small amount of $\mathrm{Cr}$ addition, a representative ferrite stabilizer, as low as $0.4 \%$ can stabilize ferrite in the temperature range from 780 to $790^{\circ} \mathrm{C}$. Consequently, ferrite formation proceeds actively in the intercritical annealing temperature range, and it is likely that austenite is further stabilized by diffusion of carbon atoms from ferrite to austenite. Under this situation, the ECO-7 and ECO-9 steels are supposed to show relatively high retained austenite volume fraction. However, their retained austenite volume fractions are below $10 \%$, and their stabilities are much lower than that of the ECO-6 and ECO-8 steels. This can be explained as follows. When $\mathrm{Cr}$ is added, the stability of austenite formed during intercritical annealing might increase, but its hardenability also increases. This case can be observed in microallying steels for hot forging, to which $\mathrm{Cr}$ is typically added in order to enhance the hardenability. Thus, when the cooling rate after the intercritical annealing is fast, most austenites are transformed to martensites to form dual phases of ferrite and martensite. In this process, a lot of carbon atoms are pinned inside martensite, and the volume fraction and stability of retained austenite decrease, since the amount of carbon atoms which can contribute to the formation of retained austenite during isothermal treatment is reduced. For this reason, the strengthening effect of dual phases overrides the TRIP effect, thereby resulting in extremely high tensile strength but poor elongation and formability. Considering that the values of $L D H_{\mathrm{o}}$ and $F L C_{\mathrm{o}}$ measured during the LDH test under no lubrication condition increase by $40-50 \%$, the formability of the ECO-7 and ECO-9 steels can be evaluated to be relatively excellent, equal to that of high-formability cold-rolled steel sheets reported by Hiwatashi et al. ${ }^{1)}$ 


\section{Conclusions}

In the present study, volume fraction and stability of retained austenite, mechanical properties, and formability were investigated for four kinds of low-carbon TRIP-aided cold-rolled steel sheets containing tramp elements such as $\mathrm{Cu}, \mathrm{Cr}$, and $\mathrm{Ni}$, and the following conclusions were reached:

(1) Formability as well as tensile properties of the $\mathrm{Cu}$ and Ni-containing cold-rolled steel sheets were greatly improved as the strain-induced transformation of retained austenite was actively sustained up to the high strain region because of high volume fraction and stability of retained austenite.

(2) The cold-rolled steel sheets to which $\mathrm{Cr}$ was added alone or in combination with $\mathrm{Ni}$ showed a dual phase structure, together with low volume fraction and stability of retained austenite resulting from a large amount of transformed martensite.

(3) When tramp elements such as $\mathrm{Cu}, \mathrm{Cr}$, and $\mathrm{Ni}$ known as harmful ones were positively applied, it was confirmed that low-carbon TRIP-aided cold-rolled steel sheets with mechanical properties suitable for various application purposes and excellent formability could be successfully fabricated.

\section{Acknowledgements}

The work was financially supported by the Ministry of Science and Technology of Korea, under the program of National Research Laboratory.

\section{REFERENCES}

1) S. Hiwatashi, M. Takahashi, T. Katayama and M. Usuda: J. Jpn. Soc. Technol. Plast., 35 (1994), 1109.

2) A. Nagasaka, K. Sugimoto, M. Kobayashi and H. Shirasawa: Tetsuto-Hagané, 84 (1998), 218.

3) K. Sugimoto, N. Usui, M. Kobayashi and S. Hashimoto: ISIJ Int., 32 (1992), 1311

4) H. C. Chen, H. Era and M. Shimizu: Metall. Trans. A, 20A (1989), 437.
5) C. G. Lee, S. G. Park, S. J. Kim and I. D. Choi: J. Korean Inst. Met. Mater, 36 (1998), 1382.

6) O. Matsumura, Y. Sakuma and H. Takechi: Trans. Iron Steel Inst. Jpn., 27 (1987), 571.

7) O. Matsumura, Y. Sakuma, Y. Ishii and J. Zhao: ISIJ Int., 32 (1992), 1110 .

8) S. Taniguchi, T. Furukawa and T. Shibata: ISIJ Int., 37 (1997), 263.

9) H. Matsuoka, K. Osawa, M. Ono and M. Ohmura: ISIJ Int., 37 (1997), 255

10) K. Shibata and Y. Mishima: ISIJ Int., 37 (1997), 197.

11) H. Ohtsuka, G. Ghosh and K. Nagai: ISIJ Int., 37 (1997), 296.

12) S. J. Seo, K. Asakura and K. Shibata: ISIJ Int., 37 (1997), 240

13) H. J. Koh, S. K. Lee, S. H. Park and N. J. Kim: Proc. of the 6th Symp. on Phase Trans., Korean Inst. Met. \& Mater., Pohang, Korea, (1996), 157.

14) S. J. Kim, C. G. Lee, T. H. Lee and C. S. Oh: ISIJ Int., 42 (2002), 1452.

15) S. J. Kim, C. G. Lee, T. H. Lee and C. S. Oh: Scr. Mater, 48 (2003), 539.

16) H. J. Koh, S. K. Lee, S. H. Park and N. J. Kim: J. Korean Inst. Met. Mater, 37 (1999), 635.

17) R. L. Miller: Trans. Am. Soc. Met., 57 (1964), 892.

18) R. L. Miller: Trans. Am. Soc. Met., 61 (1968), 592.

19) J. H. Chung: Ph.D Thesis, POSTECH, Pohang, Korea, (1993).

20) H. C. Shin, T. K. Ha and Y. W. Chang: J. Korean Inst. Met. Mater, 34 (1996), 1550.

21) A. Z. Hanzaki, P. D. Hodgson and S. Yue: ISIJ Int., 35 (1995), 79

22) K. Sugimoto, M. Misu, M. Kobayashi and H. Shirasawa: ISIJ Int., 33 (1993), 775.

23) R. A. Ayres: J. Appl. Metal Working, 1 (1979), 73.

24) R. Sowerby and J. L. Duncan: Int. J. Mech. Soc., 13 (1971), 217.

25) M. J. Painter and R. Pearce: J. Phys. D: Appl. Phys., 7 (1974), 992.

26) S. K. Kim, H. C. Shin, J. H. Chung and Y. W. Chang: J. Korean Inst. Met. Mater, 36 (1998), 151.

27) S. P. Keeler and W. A. Backofen: Trans. Am. Soc. Met., 56 (1963), 25

28) R. L. Whiteley: Trans. Am. Soc. Met., 52 (1959), 154.

29) D. B. Im, C. G. Lee, S. J. Kim and I. M. Park: J. Korean Inst. Met. Mater, 38 (2000), 447.

30) J. Y. Woo, W. Y. Choo and T. W. Park: ISIJ Int., 35 (1995), 1034

31) S. Yue, A. Dichiro and A. Z. Hanzaki: J. Met., 49 (1997), No. 9, 59.

32) Y. Kimura and S. Takaki: ISIJ Int., 37 (1997), 290.

33) N. Imai, N. Komatsubara and K. Kunishige: ISIJ Int., 37 (1997), 224.

34) Binary Alloy Phase Diagrams, 2nd Ed., Vol. 2, ed. by T. B. Massalski, ASM, Metals Park, Ohio, (1990), 1273. 